\title{
МОДЕЛЮВАННЯ УПРАВЛІННЯ ПОТОКАМИ ДАНИХ В КОРПОРАТИВНИХ ІР-МЕРЕЖАХ
}

\begin{abstract}
Анотація: Розглянуто моделі трьох методів управління мережевим трафіком, що забезпечують недопущення перевантажень телекомунікаційних каналів. В основу апаратної моделі лягла технологія обмеження потоків даних через мережеві вузли.

Ключові слова: управління мережевим трафіком; уникнення перевантажень; обмеження потоків трафіку; перевантаження телекомунікаційних каналів.
\end{abstract}

\section{Вступ}

Істотне підвищення ефективності виконання бізнес-процесів або процесів діяльності з використанням інформаційних технологій (IT) та повсюдна доступність високошвидкісних каналів доступу до мережі Iнтернет призвели до активного розвитку корпоративних розподілених IT-інфраструктур. Для моніторингу і управління IT-інфраструктурою, автоматизації процесів експлуатації обчислювальних і комунікаційних систем, а також вирішення інших завдань, що сприяють ефективному використанню інформаційних і комунікаційних ресурсів підприемства, використовуються системи управління IT-інфрраструктурою (СУІ) [1].

Активне впровадження IT для автоматизації практично всіх процесів на підприемствах спричиняе і негативні наслідки, що виявляються в перевантаженні телекомунікаційних мереж, які забезпечують інформаційну взаємодію між компонентами IT-інфрраструктури, що, в свою чергу, призводить до зниження ефективності або порушення роботи IT. Ця проблема особливо відчутна у великих корпораціях, що об'єднують багато філій і мають розвинену мережу регіональних офрісів. Корпоративні IPмережі, які об'еднують велику кількість користувачів і великі території, побудовані на основі дорогого комунікаційного обладнання, з'еднаного каналами зв'язку з обмеженою пропускною здатністю. Впровадження нових IT спричиняе збільшення навантаження на корпоративні мережі. Це супроводжуеться істотними економічними витратами на модернізацію корпоративних IP-мереж для збільшення сумарної пропускної здатності мережі. Тому однією з найважливіших задач, вирішення якої в корпоративних мережах покладається на СУІ, є управління інформаційними потоками з метою ефективного використання пропускної здатності корпоративної мережі без локальних та загальних перевантажень $[2,3]$.

\section{Аналіз існуючих рішень}

Управління інформаційними потоками найчастіше використовуеться для боротьби з мережевими перевантаженнями, що виникають при перевищенні вхідним навантаженням пропускної здатності мережі. У [4] розглядаються питання управління потоками інформації з метою запобігання втрати працездатності мережі, викликаної надмірним вхідним

(c) О.І. Ролік, Ю.М. Пошак, М.А. Никоненко, А.В. Мельник, 2011 
і транзитним трафіком, але не приділяеться уваги питанням побудови керуючого пристрою.

В [5] розглядаються питання динамічного управління ресурсами мережі на основі математичних моделей, описаних у просторі станів. Розглянуто деякі підходи до моделювання мереж: детермінований, стохастичний та адаптивний. Основний недолік даних підходів полягає у тому, що в них розглядається лише моделювання мережі, а не задача управління трафіком.

В [6] розглядаються питання перевірки ефективності управління мультимедійним TCP-трафіком, впровадженим на базі NDIS-драйвера, який забезпечуе роботу TCP-подібного протоколу в середовищі Matlab на рівні доступу до каналу зв'язку та здатен імітувати динаміку Інтернет при передачі трафріку локальною мережею. Недоліком статті є те, що динаміка роботи не враховуе програмування в значних обсягах середовища Matlab та необхідність впровадження керування на нижніх рівнях моделі OSI.

Метою статті є моделювання різних підходів до управління потоками даних в корпоративній інформаційно-телекомунікаційній мережі, що використовуе IP-протокол, та порівняння їх ефективності у вирішенні проблеми запобігання перевантаженням у мережі.

\section{Моделі управління потоками даних}

В даній статті змодельована робота трьох регуляторів, які можуть бути застосовані в СУІ. Моделі перша та друга - апаратний та програмний регулятори, робота яких відповідае алгоритмам, що використовуються в мережевому обладнанні. Третя модель - оптимальний по швидкодії регулятор, що реалізуе підхід до управління інформаційними потоками, який базуеться на застосуванні методів теорії автоматичного управління (ТАУ).

Апаратний регулятор виконаний за аналогією з існуючим методом управління трафріком у маршрутизаторах - policing, якій здійснюе затримку або відкидання пакетів з метою обмеження навантаження на канали зв'язку. Управління реалізуеться шляхом обмеження інформаційного потоку у випадку перевищення ним заданого рівня. Таким чином частина даних, що передавались, відкидається.

Модель системи управління з апаратним регулятором наведена на рис. 1.

В даному випадку регулятор працюе таким чином: якщо після порівняння бажаної та реальної величини потоку інформації виникає потреба обмежити потік, то весь трафік, який перевищуе задану величину, відкидаеться і на виході отримуеться необхідне значення. На рис. 2 потік обмежений рівнем значення задаючого впливу, що дорівнюе 1.

Перевагою цього способу управління потоками $е$ простота реалізації та універсальність регулятора, оскільки він аналогічним чином управляе всіма видами трафіку. Проте істотним недоліком е те, що таке управління не є регулюванням, воно швидше зводиться до обмеження у випадках 


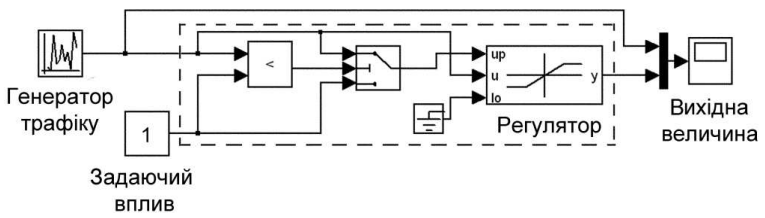

Рис. 1 - Модель систем управління потоками трафіку на основі апаратного регулятора.

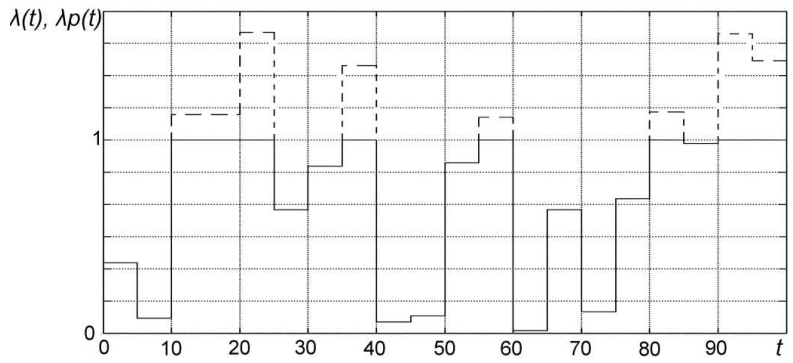

Рис. 2 - Перехідна характеристика систем управління потоками трафіку на основі апаратного регулятора (суцільною лінією позначено трафік після обмеження $\lambda_{p}(t)$, пунктирною - вхідний потік $\lambda(t)$.

перевантажень у каналах передачі даних. Тобто не виробляеться ніяка управляюча дія, яка, за необхідності, синтезувала б керуючі сигнали для генераторів трафіку про потребу зменшення кількості інформації, що передається, з метою уникнення перевантажень, втрат інформації та повторної передачі. Такий шлях, зрештою, призводить до надлишкового неефективного використання комунікаційних ресурсів та зниження ефективності функціонування розподілених застосувань.

В програмному регуляторі (див. рис. 3) управління відбувається таким чином: якщо після порівняння бажаної та реальної величини потоку даних виникає потреба обмежити потік, то регулятор поступово знижує коефріцієнт передачі доти, доки потік не буде достатньо обмежено. Проте, у зв'язку з особливостями даного методу, виникае затримка винесення рішення, що обумовлена необхідністю постійного аналізу стану каналів, збору інформації про пакети, що надійшли, та ін. При цьому виникає ситуація, коли потік вже достатньо обмежено, але через відсутність інформації про стан каналів, яка ще не отримана, додатково продовжуеться обмеження потоків. Після цього регулятор з'ясовуе, що потоки занадто обмежені та здійснює стрибкоподібне підвищення коефіцієнту передачі. У зв'язку з цим отримуемо пилоподібну завантаженість каналів зв'язку, яку можна спостерігати на рис. 4.

Перевагою цього регулятора є універсальність, оскільки він дозволяє 


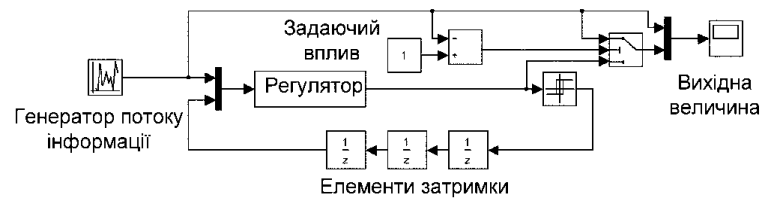

Рис. 3 - Модель систем управління потоками трафіку на основі програмного регулятора.

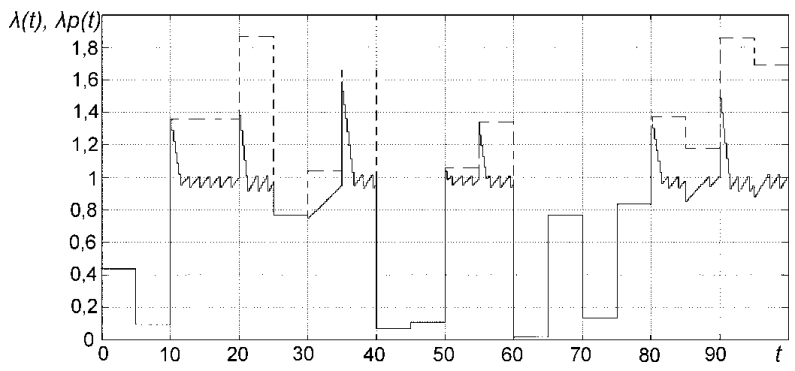

Рис. 4 - Графік залежності величини потоків інформації від часу, в системі з програмним регулюванням (суцільна лінія $\lambda_{p}(t)$ і без нього (пунктирна лінія $\lambda(t)$. Бажана завантаженість каналу дорівнюе 1.

регулювати різні типи трафріку. Недоліком є високий вплив на якість керування затримок, що виникають при зборі та обробці інформації і розповсюдженні керуючого впливу. Оскільки зміна коефіцієнту відбувається лінійно, великі затримки спричиняють несвоєчасну і невідповідну управляючу дію.

Перспективним у вирішенні задачі управління потоками мережевого трафріку є використання принципів та методів теорії автоматичного управління. Для того, щоб розглянути мережу передачі даних та СУІ з точки зору ТАУ, необхідно представити їх як систему автоматичного регулювання (САР). Дослідження будь-якої САР починаеться з формалізації понять і об'єктів, а також з формулювання цілей та критеріїв управління.

Класична схема САР містить об'єкт регулювання (ОР) та пристрій управління, який, аналізуючи регульовану величину (тобто вихід об'єкту управління, що подається на регулятор за допомогою зворотного зв'язку) та вихідний вплив, синтезуе необхідне управління. Формалізуючи задачу управління потоками, визначимо, що об'єктом управління $\epsilon$ станція, підмережа чи будь-яка сукупність об'єктів мережі, що генерують потоки інорорації; вихідна (регульована) величина - величина завантаженості каналу зв'язку; вхідний вплив - пропускна здатність каналу передачі інформації; помилка системи - величина перевантажень, що 
виникають в мережі при надмірних потоках інформації. Метою керування $е$ мінімізація помилки системи за максимально короткий проміжок часу. Дану систему можна класифікувати як різновид дискретної системи стабілізації, оскільки при відсутності перевантажень система не потребуе управління потоками, у протилежному ж випадку - регулятор намагається підтримувати стабільне значення величини потоку інформації не вище заданого вхідного впливу.

Ключовим моментом е визначення математичної моделі, що належним чином описуе поведінку ОР. Зазвичай, така математична модель являе собою диференційне рівняння чи систему диференційних рівнянь, що характеризують динаміку об'єкту управління залежно від різних вхідних впливів. В реальних мережах генерування трафіку - це стохастичний процес. Єдиний спосіб, яким так чи інакше можна вплинути на величину потоку інформації, - обмежити його. Саме значення цього обмеження залежно від величини перевантажень та затримок в мережі і $\mathrm{e}$ кінцевим управляючим впливом.

Математична модель заданого об'єкту управління описується цифровою передатною функцією:

$$
\begin{aligned}
& W_{O P}(z)=\frac{\left(0.17 z^{2}-0.17945124 z+0,5448581\right)\left(z^{2}-1,86343304 z+1,0272802\right)}{\left(z^{2}-0,6899688 z+0,99999679\right)\left(z^{2}-1,90008393 z+1,00004419\right)} . \\
& \cdot \frac{\left(z^{2}-1,97367732 z+1,0001752\right)}{\left(z^{2}-1,97291917 z+0,99995902\right)} .
\end{aligned}
$$

Знаючи передатну функцію ОР і обравши бажані характеристики замкненої системи, можна синтезувати регулятор, що забезпечить кінцевій системі необхідні показники якості. В даному випадку, бажаними показниками якості е відсутність статичної помилки та максимальна швидкодія системи. Відповідно до цього і буде синтезуватись регулятор.

Замкнена система описуеться таким виразом:

$$
W_{3}(z)=\frac{W_{P}(z) \cdot W_{O P}(z)}{1+W_{P}(z) \cdot W_{O P}(z)},
$$

де $W_{O P}(z)$ - передатна фрункція $\mathrm{OP}, W_{3}(z)$ - передатна функція замкненої системи, $W_{P}(z)$ - передатна функція регулятора.

Передатну функцію регулятора можна представити як

$$
W_{P}(z)=\frac{W_{3}(z)}{W_{O P}(z) \cdot\left(1-W_{3}(z)\right)} .
$$

Синтез регулятора виконується в кілька етапів.

Перший етап - фракторизація передатної функції об’екту регулювання:

$$
W_{O P}(z)=\frac{B(z)}{C(z)}=\frac{B(z)}{(z-1)^{r_{0}} \cdot C^{-}(z) \cdot C^{+}(z)},
$$

де поліноми $C^{-}(z)$ та $C^{+}(z)$ мають нулі поза кругом і в крузі одиничного радіуса відповідно; $r_{0}$ - степінь астатизму.

Для об'єкту, що розглядається, всі корені лежать поза кругом одиничного радіусу, тому $C^{-}(z)=1$. 
Другий етап - вибір виду бажаної передатної функції замкненої системи. 3 можливих варіантів обираємо той, який забезпечить бажаний процес у будь-які моменти часу та надасть системі астатизм порядку $r=1$ по заданому вхідному впливу. Бажана передатна функція замкненої системи такого типу описуеться таким виразом:

$$
W_{3}(z)=\frac{B(z) \cdot M(z)}{Q(z)} .
$$

де $M(z)$ - поліном; $Q(z)$ - характеристичний поліном замкненої системи.

Помилка системи описуеться виразом (6)

$$
1-W_{3}(z)=\frac{(z-1)^{r} \cdot C^{-}(z) \cdot N(z)}{Q(z)},
$$

де $N(z)$ - поліном.

Характеристичний поліном для системи з максимальною швидкодією знаходиться за формулою:

$$
Q(z)=z^{k},
$$

де

$$
\begin{gathered}
K=\|B\|+\left\|C^{-}\right\|+r=6+0+1=7, \\
Q(z)=z^{7} .
\end{gathered}
$$

Степені поліномів $M(z)$ та $N(z)$ визначаються таким чином:

$$
\begin{aligned}
& \|M\|=\left\|C^{-}\right\|=0, \\
& \|N\|=\|B\|=6
\end{aligned}
$$

Відповідно поліноми $M(z)$ та $N(z)$ набувають такого вигляду:

$$
\begin{aligned}
& M(z)=m_{0}, \\
& N(z)=n_{6} z^{6}+n_{5} z^{5}+n_{4} z^{4}+n_{3} z^{3}+n_{2} z^{2}+n_{1} z+n_{0} .
\end{aligned}
$$
ність

Для визначення значень коефіціентів поліномів (11) використаємо рів-

$$
B(z) \cdot M(z)+(z-1) \cdot C_{1}^{-}(z) \cdot N(z)=Q(z) .
$$

Підставивши (9) та (11) в (12) і розв'язавши (12), отримаємо коефіціенти шуканих поліномів: 


$$
\begin{aligned}
& m_{0}=430,19578640435048394874991557408, \\
& n_{0}=240,83220514488348792418917773668, \\
& n_{1}=-750,58581050822039618450753122253, \\
& n_{2}=962.24998935265428649232552226844, \\
& n_{3}=-662,17621722822273644958557088917, \\
& n_{4}=285,68636361094297625792474413030, \\
& n_{5}=-72,133283688739582271287485647593, \\
& n_{6}=1 .
\end{aligned}
$$

3 виразу (3), з урахуванням (4) - (6), отримуемо наступну формулу для обчислення передатної функції регулятора:

$$
W_{P}(z)=\frac{(z-1)^{r_{0}-r} \cdot C^{+}(z) \cdot M(z)}{N(z)} .
$$

Підставивши всі необхідні дані з (14), отримуемо розраховану передатну характеристику регулятора:

$$
\begin{aligned}
& W_{P}(z)=\frac{430,196 z^{6}-2083,008 z^{5}+4517,761 z^{4}}{z^{7}-73,133 z^{6} 6+3575,82 z^{5}-947,86 z^{4}+} \\
& \frac{-5728,698 z^{3}+4517,76 z^{2}-2083,008 z+430,196}{1624,4 z^{3}-1712,8 z^{2}+991,42 z-240,83} .
\end{aligned}
$$

Результат моделювання системи з розрахованим регулятором у середовищі Matlab зображений на рис. 5 та 6.

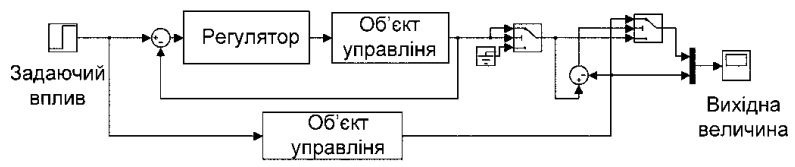

Рис. 5 - Модель систем управління потоками трафріку на основі оптимального по швидкодії регулятора.

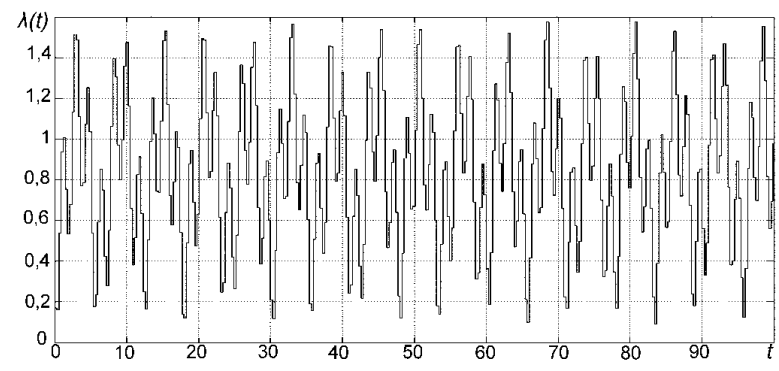

Рис. 6 - Перехідна характеристика системи без регулятора.

Використання регулятора, побудованого на основі методів ТАУ, для управління трафіком дозволило отримати швидкий процес регулювання 


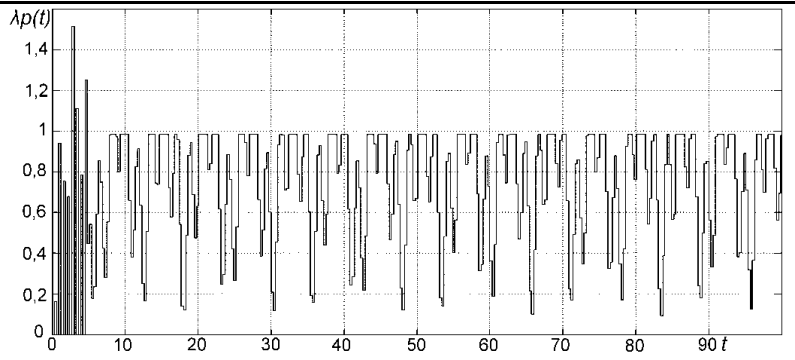

Рис. 7 - Перехідна характеристика систем управління потоками трафіку на основі оптимального по швидкодії регулятора.

з установленим значенням, яке знаходиться в заданих межах. Недоліком такого регулятора $\varepsilon$ ефективна робота лише з чітко описаним об'єктом управління, оскільки тільки за таких умов будуть досягатися бажані критерії якості роботи системи. У реальних компютерних мережах чітко описати об'єкт управління, що здійснюе генерацію трафріку, неможливо, а будь-яке його математичне представлення є лише наближенням.

Можливість застосування ТАУ в сфері телекомунікаційних мереж загалом, та для вирішення поставленої задачі зокрема, викликає безперечний інтерес, оскільки математичний апарат ТАУ дозволяє досить чітко розрахувати керуючий пристрій, що надає системі бажаних показників якості навіть за умови наявності затримок в системі.

Після моделювання описаних вище підходів до управління потоками інформації в мережі можна виконати порівняння даних регуляторів за такими критеріями: швидкодія регулятора, тобто швидкість, з якою регулятор виробляє необхідну керуючу дію; вплив затримок передачі даних на своєчасність регулюючої дії; види трафіку, які здатен регулювати регулятор; простота реалізації та розрахунку регулятора; ефективне використання наявних мережевих ресурсів.

За швидкістю вироблення управляючої дії перша модель беззаперечно займае лідируючу позицію, оскільки не потребуе глибокого аналізу ситуації i, відповідно, часу на вироблення та передачу управляючої дії, оскільки обмеження відбувається одразу при перевищенні пропускної здатності каналу передачі інформації. Інші два регулятора у разі значних затримок при передачі керуючої дії не можуть повністю виключити перевантаження, у другій моделі такі затримки спричиняють пилкоподібний вигляд встановленого значення завантаженості каналу.

Максимальне використання пропускної здатності каналу зв'язку відбувається у першій моделі, оскільки канал завантажуеться повністю аж до появи перевантажень, у той час як в інших двох моделях при появі надмірної кількості потоків відбувається часткове розвантаження каналу за рахунок реалізації управління. Але в даному випадку не можна говорити про найефективніше використання ресурсів першою моделлю, оскільки за відсутності регулювання інтенсивності потоків, при 
перевантаженнях з'являеться необхідність повторної передачі відкинутих даних. Таким чином, повторно виконуеться передача, що знову веде до використання мережевих ресурсів. Тому говорити про ефективне використання ресурсів мережі в першій моделі не можна. Набагато менше перевантажень, а отже, і необхідності повторної передачі пакетів даних, відбувається в моделях другій та третій, що, у свою чергу, свідчить про ефективніше використання ресурсів мережі.

За складністю розрахунку та реалізації останній, розрахований за допомогою методів ТАУ, регулятор є найскладнішим. Але якість регулювання трафріку таким регулятором набагато вища за всі попередні моделі. Найбільшим недоліком цього регулятора є можливість роботи лише з чітко заданим трафіком. В той час, як види потоків трафіку, що регулюються першою та другою моделями регуляторів, не обмежені, за винятком випадку, коли час, необхідний регулятору на корекцію коефіцієнту передачі, на порядок менший за час зміни величини потоку.

\section{Висновки}

В роботі розглянуто різні підходи до моделювання управління потоками даних в комп'ютерних мережах. Розроблено три моделі управління потоками. Визначені переваги і недоліки кожної моделі та їх сфери застосування. Апаратна модель відрізняеться простотою реалізації та високою швидкодією, але вона позбавлена можливості генерування управляючих команд для джерел трафріку. Модель на основі програмного регулятора має можливість впливати на генерацію трафіку, але їі неможливо адаптувати до затримок при прийнятті рішень, які призводять до неефективного управління на надлишкових втрат. Модель, що побудована з використанням методів ТАУ, здатна адаптуватися до затримок, що виникають при виробленні управляючої дії.

Наступним етапом дослідження може бути синтез регулятора, що зможе працювати з неповністю або нечітко описаними об'єктами, які змінюють свою структуру та параметри у часі.

\section{Література}

1. Теленик С.Ф. Система управління інформаційнотелекомунікаційною системою корпоративної АСУ / С.Ф. Теленик, О.І. Ролік, М.М. Букасов, Р.Л. Соколовський // Вісник НТУУ “КПІ". Інформатика, управління та обчислювальна техніка. - 2006. - 45. C. $112-126$.

2. Ролик А.И. Система управления информационными потоками в корпоративной IP-сети / А.И. Ролик, В.А. Иосифов / Адаптивные системы автоматического управления. Межвед. науч.-техн. сб. - Днепропетровск: Системные технологии, 2009. - Вып. 14(34). - С. 73-85.

3. Ролик А.И. Модель подсистемы управления информационными потоками с адаптивным регулятором/ А.И. Ролик, Ю.Н. Пошак, М.А. Никоненко, А.В. Мельник // Адаптивні системи автоматичного 
управління. Міжвідомчий науково-технічний збірник. - Дніпропетровськ: Системні технології, 2010. - Вип. 16(36). - С. 94-103.

4. Дымарский Я.С. Управление сетями связи: принципы, протоколы, прикладные задачи / Я.С. Дымарский, Н.П. Крутякова, Г.Г. Яновский // М.: ИТЦ “Мобильные коммуникации”. - 2003. - 384 с.

5. Поповский В.В. Динамическое управление ресурсами TКС: математические модели в пространстве состояний / В.В. Поповский, А.В. Лемешко, О.Ю. Евсеева // Науково-виробничий збірник "Наукові записки Українського науково-дослідного інституту зв'язку”. - 2009. 1(9). - C. $3-26$

6. Аноприенко А.Я. Многоуровневое моделирование сетей на базе стека протоколов TCP/IP в среде Matlab/Simulink / A.Я. Аноприенко, С.Н. Джон, А.Ж. Нури // Науч. труды ДонНТУ. Вып. 39. Сер.: Информатика, кибернетика и вычислительная техника (ИКВТ-2002):Донецк: ДонНТУ, 2002. - С. 271-279.

Отримано 09.03.2011 p. 